\title{
A CONSTRUÇÃO DISCURSIVA DOS DIREITOS HUMANOS E SUAS TENSÕES: O CASO DA EXTREMA DIREITA NO BRASIL
}

\section{THE DISCURSIVE CONSTRUCTION OF HUMAN RIGHTS AND ITS TENSIONS: THE CASE OF THE EXTREME RIGHT IN BRAZIL}

\section{Maria Clara Gomes M. Cavalcanti Ruberval Ferreira**}

\section{RESUMO}

O presente trabalho investiga as formas de produção de sentido para os direitos humanos no discurso da extrema direita no Brasil com foco na dimensão ideológica dos processos em questão e seus efeitos na construção de uma nova hegemonia. A discussão toma como referência a Análise de Discurso Crítica, na vertente de Fairclough ([1992] 2001; 2003), em diálogo com a Teoria do Discurso de Ernesto Laclau (LACLAU, MOUFFE [1985] 2015; LACLAU 1990; 2013). A discussão mostra que a construção discursiva dos direitos, para além do âmbito normativo, não apenas se dá em variadas mobilizações práticas, como envolve disputas de sentido e de poder, sendo parte fundamental da construção e transformação de sistemas de significação contemporâneos. A análise aponta que a (re) construção discursiva dos direitos humanos, no contexto do populismo de extrema direita emergente no Brasil atual, integra uma articulação discursiva cujos momentos (e os direitos humanos constituem uma das diferenças articuladas) caracterizam-se, sobretudo, por um esvaziamento de seus conteúdos.

Palavras-chave: direitos humanos; discurso político; hegemonia; representação.

\section{ABSTRACT}

This study investigates the meanings of human rights in the extreme right speech in Brazil focusing on the ideological dimension of this processes and its effects on the construction of a new hegemony. The discussion is based upon Critical Discourse Analysis, from Norman Fairclough ([1992] 2001; 2003), in dialogue with Ernesto Laclau's Discourse Theory (LACLAU; MOUFFE [1985] 2015; LACLAU 1990; 2013) as theoretical references. The results indicate that the discursive construction of human rights, beyond the normative scope, occurs in several practical mobilizations, involves meaning and power disputes and is a fundamental part of the contemporary construction and transformation of meaning

\footnotetext{
* Universidade Federal do Ceará, UFC, Fortaleza, CE, Brasil. mclaragomes@ufc.br Orcid: https://orcid.org/0000-0002-1469-7078

** Universidade Estadual do Ceará, UECE, Fortaleza, CE, Brasil. ruber.ferreira@uece.br Orcid: https://orcid.org/0000-0002-3588-7321
} 
systems. According to the analysis, the discursive construction of human rights, in the context of emerging extreme right populism in Brazil today, integrates a discursive articulation characterized by an emptying of its significance.

Keywords: human rights; political discourse; hegemony; representation.

\section{CONSIDERAÇÕES INICIAIS}

Em seu discurso de posse proferido no planalto, o atual presidente brasileiro menciona, como parte dos desafios a serem enfrentados por seu governo, o que ele chama de "desvirtuamento dos direitos humanos" e "desconstrução da família". Desse trecho de sua fala, pode-se extrair, como pressuposto necessário, uma tese fundamental deste trabalho: a tese de que a construção discursiva dos direitos humanos, para além do âmbito normativo, se dá em suas mais variadas mobilizações práticas, envolvendo sujeitos e contextos reais. Esse conjunto de direitos pode ser "interpretado" de maneiras diversas, revestido de sentidos diferentes, em função de configurações de forças e lutas por poder. Assim, além de institutos jurídicos (e sobretudo nessa condição), os direitos humanos são discurso, são construções discursivas, mobilizados e (re)significados a serviço de projetos hegemônicos.

Gestados tendo como fundamento e legitimidade uma representação universal, i.e, uma visão essencialista do humano, há algumas décadas, é no seio das lutas por direitos que se têm formado novas articulações identitárias geradoras de novos sentidos para direitos humanos. A afirmação da diferença, a defesa da diversidade, o domínio das singularidades, da particularização são as marcas mais evidentes dos contextos de luta a favor dos direitos humanos. Hoje, representam os direitos das minorias, dos grupos marginalizados, daqueles que não têm direitos. Constituem, assim, para além de um sistema jurídico internacional de regras e princípios, uma bandeira de luta e afirmação da dignidade humana, em confronto com visões que sustentam desigualdades, exclusões e formas de dominação com origem no investimento ideológico da diferença.

Neste trabalho, analisamos os sentidos de direitos humanos em construção nos discursos políticos inaugurais do presidente Jair Bolsonaro. Quando os direitos humanos são pinçados para o interior da fala do presidente, como iremos demonstrar, pode-se perceber um novo movimento nesse processo de reconstrução do sentido de direitos humanos. Esse movimento é desferido não para reforçar sua higidez e a história de sua afirmação, mas para esvaziar seu sentido. Em face dessa constatação, consideraremos, neste trabalho, os direitos humanos como "pontos nodais" (LACLAU, 2013) dos discursos engendrados no cenário político do Brasil atual, isto é, como um elemento privilegiado de significação a partir do qual outros 
elementos são ordenados. Em sua fala, o presidente demarca sua identificação com um grupo de eleitores, que reconhecem o conservadorismo presente em seu discurso e sentem-se por ele representados. Esse gesto faz convergir, em uma simples referência, múltiplos significados para a fala do presidente, o que o torna relevante na construção de um projeto hegemônico.

Procuramos demonstrar que, por intermédio das próprias escolhas linguísticas envolvidas, são silenciados diversos sentidos associados aos direitos humanos - seu estatuto jurídico, sua positividade e higidez, a história de sua construção - e um sentido negativo, associado a opiniões de extrema direita, é alavancado, a fim de gerar adesão em face de um conjunto de indivíduos. Uma parte da argumentação presente neste trabalho quer demonstrar que há uma estratégia de (re)construção de sentidos colocada a efeito na fala do presidente, assim como em outros discursos que se articulam, de modo a servir ao projeto de poder vigente no Brasil.

Diante desse panorama, os direitos humanos, a par de corresponderem a um sistema de normas e princípios do direito internacional de elevada importância na ciência jurídica e no ordenamento das sociedades contemporâneas, são uma construção sócio-histórica e discursiva que tem sido ressignificada em discursos diversos. De fato, eles são frequentemente mobilizados em práticas discursivas variadas, tais como: o discurso institucional das ações de gestão do Poder Público, o discurso político eleitoral dos representantes eleitos, as práticas de militância, o discurso cotidiano nas comunidades locais que convivem com formas de violação, o discurso midiático, o discurso intergovernamental ou geopolítico de relações entre Estados-nação, entre tantos outros. Portanto, parte-se aqui da compreensão de que a construção discursiva dos direitos humanos se dá não somente no discurso jurídico das normas internacionais, mas também, e principalmente, em suas mais variadas mobilizações práticas, envolvendo sujeitos e contextos reais. Por ser uma construção de discurso, os direitos humanos estão enredados, assim, em disputas por sentidos e por poder, sendo parte fundamental da construção e da transformação de sistemas de significação contemporâneos.

A discussão toma como referência principal a Análise de Discurso Critica (doravante ADC) na vertente proposta por Norman Fairclough ([1992] 2001; 2003), para quem o discurso é um elemento indissociável das práticas sociais, interconectado a outros elementos. Articulamos, até onde isso é possível, algumas questões levantadas no âmbito da ADC com outras questões postas pela Teoria do Discurso de Ernesto Laclau (LACLAU, MOUFFE, [1985] 2015; LACLAU, [1990] 2013), sobretudo no que concerne às discussões sobre hegemonia, antagonismo e populismo. No que diz respeito ao principal aporte teórico dessa discussão, 
procuramos vislumbrar as relações entre discurso e ideologia, observando o confronto de forças e vontades opostas, a demarcação de fronteiras e as disputas por poder travadas no interior do discurso (e fora dele), para construir novos sentidos para direitos humanos.

Os textos que constituem o corpus principal da análise aqui proposta são dois discursos inaugurais do presidente brasileiro, à época recém-eleito: seu discurso de posse, proferido no planalto em $1^{\circ}$ de janeiro de 2019 ; e o discurso proferido no primeiro pronunciamento internacional do presidente, no Fórum Econômico Mundial, em 22 de janeiro de 2019. Além de considerar as escolhas linguísticas e estratégias de significação mobilizadas nestes textos, procuramos considerar, segundo Fairclough (2003), a relação entre tais discursos e a ampla rede de práticas sociais com as quais eles se relacionam. O foco da análise recai sobre as representações construídas nos discursos políticos mencionados, estratégias exploradas por Fairclough (2003) no que ele chama de significado representacional.

Entendemos que as representações selecionadas para construir a fala do presidente, assim como o modo como essas representações são qualificadas e relacionadas entre si contribuem para depreciar o sentido de direitos humanos, menosprezando seu status jurídico, assim como sua historicidade e higidez. Ao ampliar o foco da análise para além dos textos e em direção à rede de práticas sociais concretas que caracterizam o cenário político brasileiro - o horizonte de desmonte e ameaça a direitos, de desrespeito a conquistas históricas -, entendemos os empreendimentos discursivos analisados como um conjunto de estratégias simultaneamente discursivas e políticas que têm sido usadas a serviço de um projeto de poder cuja hegemonia se dá em função da ideologia de extrema direita no Brasil.

Na seção seguinte, trataremos brevemente da história da construção e justicialização ${ }^{1}$ dos direitos humanos, a fim de situar a concepção contemporânea acerca desse conjunto de direitos e estabelecer uma relação entre esse processo e as práticas discursivas. Tornaremos, assim, explícita a metodologia de análise empregada neste trabalho, esclarecendo quais conceitos e categorias de análise discursiva são aqui empregados para lançar luz sobre a construção discursiva dos direitos humanos diante do cenário político brasileiro. Em seguida, apresentamos a análise dos dados oriundos dos textos selecionados, ressaltando sua pertinência para pensar a relação entre discurso, hegemonia e poder. Por fim, apresentamos as

1. Expressão empregada por teóricos como Flávia Piovesan (2011) e Celso Lafer (1988) para referirse ao processo complexo de construção de uma justiça internacional dos direitos humanos, abrangendo um sistema de normas positivadas, assim como um conjunto de órgãos jurisdicionais, no âmbito internacional e regional - sistemas regionais europeu, interamericano e africano - com capacidade sancionatória diante de ameaças a direitos. 
considerações finais, dando destaque às reflexões fundamentais que procuramos lançar neste trabalho.

\section{A CONSTRUÇÃO DE UMA JUSTIÇA INTERNACIONAL DOS DIREITOS HUMANOS: DAS ORIGENS À CONCEPÇÃO CONTEMPORÂNEA}

O contexto histórico do qual emerge a concepção contemporânea de direitos humanos diz respeito a uma resposta jurídica a ações bárbaras de violação empreendidas no período da Segunda Guerra Mundial. A história registra um período de descartabilidade do ser humano, diante da lógica da destruição, encenada no palco da humanidade. $\mathrm{O}$ aspecto fundamental a ser apontado nessa origem de um sistema de direitos universais, acima dos ordenamentos internos, assegurador de valores fundamentais, mais altos que as vontades coletivas de cada Estado de direito em particular, diz respeito ao fato de que a lei oriunda dos Estados de direito, por si só, foi posta em xeque diante dos acontecimentos históricos. Os absurdos testemunhados nos governos totalitaristas foram cometidos diante da (e apesar da) lei; isto é, apresentavam o próprio Estado figurando como maior violador. Segundo Piovesan:

A barbárie do totalitarismo significou a ruptura do paradigma dos direitos humanos, por meio da negação do valor da pessoa humana como valor-fonte do Direito. Se a Segunda Guerra significou a ruptura com os Direitos Humanos, o Pós-Guerra deveria significar sua reconstrução (PIOVESAN, 2011, p. 37).

A Declaração Universal dos Direitos Humanos², adotada e proclamada pela Resolução n. 217 A (III) da Assembleia Geral das Nações Unidas, em 10 de dezembro de 1948, consagrou esse anseio e originou o marco inicial do desenvolvimento do direito internacional dos direitos humanos. Esse instrumento normativo, que consagra a revisão da noção tradicional de soberania absoluta dos Estados e a sedimentação da ideia de que o indivíduo é sujeito de direitos protegidos na esfera internacional, fornece lastro axiológico para os demais dispositivos que se sobrevieram em meio ao processo de justicialização dos direitos humanos na ordem internacional: o Pacto Internacional dos Direitos Civis e Políticos, o Pacto Internacional dos Direitos Econômicos, Sociais e Culturais, assim como uma série de outros tratados e convenções (PIOVESAN, 2011).

Além da construção desse conjunto de normas jurídicas internacionais, importantes acontecimentos históricos também marcaram o desenvolvimento e a

2. Disponível em: https://www.ohchr.org/EN/UDHR/Pages/Language.aspx?LangID= por 
afirmação cada vez mais veemente dessa ordem de direitos sobre o mundo. Trata-se dos esforços empreendidos para criar um efetivo sistema jurisdicional internacional que se impusesse concretamente sobre as nações a fim de assegurar o cumprimento e o respeito à ordem internacional de direitos humanos. As experiências seminais mais significativas nesse sentido foram a criação do Tribunal de Nuremberg, a criação dos Tribunais ad hoc para a ex-Iugoslávia e para Ruanda, a criação do Tribunal Penal Internacional, e a geração dos sistemas regionais de proteção dos direitos humanos - sistemas europeu, interamericano e africano.

É importante mencionar, ainda, dentro deste panorama histórico, que, aliada ao empenho de afirmação e positivação dos direitos humanos no âmbito da justiça internacional, deu-se a emergência de uma renovada vertente de um constitucionalismo global (ou, melhor dizendo, ocidental), fortemente marcado por valores e princípios orientadores da ordem jurídica interna, com foco sobre a dignidade humana, como princípio motriz. A imbricação do direito internacional com o constitucional também se apresenta como fenômeno do pós-guerra e como parte substancial do contexto de reconstrução dos direitos humanos, gerando uma depreciação de valores como o interesse nacional ou a soberania estatal, em face de interesses teleológicos de construção de ordens jurídicas mais democráticas, socialmente justas e ambientalmente responsáveis, assim como de edificação de Estados internacionalmente cooperantes.

Diante desses precedentes históricos, assim como dos desafios do presente, fala-se atualmente em uma "concepção multicultural dos direitos humanos" (SOUZA SANTOS, 2009), direitos humanos como uma "racionalidade de resistência" (FLORES, 1991), "plataforma emancipatória" de direitos (PIOVESAN, 2011), entre outras perspectivas. É impossível desconsiderar, no tempo presente, o processo contínuo de construção e reconstrução dos direitos humanos nas práticas sociais concretas, desde seu caráter normativo, seu processo de positivação e afirmação como ordem jurídica que se sobreleva ao mundo, até as ações de militância, a luta em defesa desse rol de direitos, o chão em que eles se materializam e que tem se configurado como parte fundamental da sua construção no contemporâneo.

Autores como Boaventura de Souza Santos defendem que um caminho possível para o trato da problemática dos direitos humanos passa pela via do multiculturalismo. Esta noção é tomada como condição prévia para o advento de relações mais equilibradas e mutualmente potenciadoras entre competência global e legitimidade local (SOUZA SANTOS, 2009, p. 112). Assim, pela adoção de uma consciência mais viva da incompletude cultural de cada povo, abrir-se-ia a 
via possível para o diálogo, gerando um caminho para que essa ordem de direitos pudesse ser reconceptualizada como direitos multiculturais.

Assim também sustentam autores como Joaquín Herrera Flores (1991) com sua proposta de um universalismo de confluência. Sua visão dos direitos humanos, baseada no que ele denomina "racionalidade de resistência", reafirma a possibilidade de alcançar uma síntese universal das diferentes opções relativas a direitos. Contudo, a afirmação desse universalismo não pode ser concebida como ponto de partida, mas sim de chegada, por meio de um processo conflitivo, discursivo de diálogo (FLORES, 1991, p. 7).

\section{A CONSTRUÇÃO DISCURSIVA DOS DIREITOS HUMANOS NO DISCURSO POLÍTICO DO PRESIDENTE}

Diante dessa visão contemporânea sobre os direitos humanos, marcada por contingências históricas e reformulações contínuas em meio a épocas, culturas e povos, apontamos a pertinência do discurso como parcela irredutível desse processo. Partimos, neste trabalho, do pressuposto de que neste amplo processo de (re)construção do sentido de direitos humanos somos confrontados com questões de linguagem, em sua relação indissociável com a vida social. Trata-se de conceber a linguagem como discurso, com seu potencial de ação e intervenção sobre o mundo, tendo como suporte, para isto, uma instância discursiva do campo jurídico: os direitos humanos.

Partindo do aporte teórico da ADC e sua visão do discurso inserido em (redes de) práticas sociais, entendemos que o(s) sentido(s) de direitos humanos são construídos e reconstruídos em meio aos discursos que circulam no contemporâneo. Inseridos em redes de práticas sociais particulares - prática discursiva midiática, política, jurídica, diplomática, educacional entre tantas outras - tais discursos retextualizam e ressignificam os direitos humanos. Assim, além de institutos jurídicos de índole internacional com elevada higidez e status em face do regime jurídico nacional, esse conjunto de direitos, segundo o prisma deste trabalho, é tomado como uma construção discursiva em curso no contemporâneo. Em diálogo com Ernesto Laclau e Chantal Mouffe (2015) indagamo-nos neste trabalho sobre a possibilidade de se considerar direitos humanos como um significante vazio (empty signifier), uma vez que seus sentidos são preenchidos dentro dos limites contingentes das tensões sociais, das lutas pelo controle dos sentidos do mundo social, enfim, da luta por hegemonia. 
Portanto, neste trabalho, o foco das análises recai sobre a faceta propriamente discursiva da construção contemporânea dos direitos humanos, a partir de sua mobilização em um contexto bem particular: nos discursos políticos inaugurais proferidos pelo presidente da república. A escolha dessa instância de análise relaciona-se com o teor perigoso do discurso ultraconservador da extrema direita que foi salientado no Brasil, como gesto de força política, tendo como centro irradiador o atual presidente. Uma análise, ainda que superficial, da conjuntura que se apresenta em nosso país, sinaliza um grave cenário de ameaças a direitos, de retrocessos em conquistas históricas, notadamente na proteção da dignidade humana, da equidade, da distribuição de renda, da valorização dos trabalhadores etc. Defendemos, neste trabalho, que uma parcela importante e crucial dessa problemática diz respeito aos discursos que emanam da figura do presidente e de seus aliados políticos, contribuindo para instaurar, legitimar, perpetuar assimetrias, exclusões e violências.

Para colocar em efeito esta análise simultaneamente discursiva e social dos discursos do presidente, atentando para as relações que podem ser estabelecidas entre as noções de discurso e hegemonia, empregamos as categorias analíticas e conceitos propostos por Fairclough (2003), em sua discussão sobre o que ele chama de significado representacional. Para Fairclough, um modo do discurso figurar em meio às práticas sociais diz respeito às formas de representação do mundo empreendidas no discurso, às visões de mundo selecionadas, o modo como encontram-se relacionadas. Submeteremos os dois textos selecionados no corpus - dois discursos políticos inaugurais do presidente Bolsonaro - a uma análise dos significados representacionais produzidos, procurando relacionar as estratégias linguísticas neles presentes com a saliência de ideologias de extrema direita, a serviço de um projeto de poder. Passemos à análise.

\section{INTERDISCURSIVIDADE, REPRESENTAÇÃO E HEGEMONIA NO DISCURSO DE JAIR BOLSONARO SOBRE DIREITOS HUMANOS}

Uma das mais proeminentes diferenças entre o modo de tratamento da linguagem proposto pela Análise de Discurso Crítica e outras perspectivas que focam a linguagem em sua dimensão sócio-histórica é a orientação para a análise material de textos. A ADC, nos trabalhos de Fairclough (2003), propõe, por intermédio do diálogo teórico e metodológico com a Linguística Sistêmica Funcional, que tem seu maior representante em Halliday (1994), uma série de categorias analíticas para uma compreensão do que esse modelo de análise chama de três formas de significação 
implicadas no discurso, a saber: o significado representacional, o significado acional e o significado identificacional. Através dessas categorias, o analista crítico de discurso pode investigar a relação discurso/sociedade em ocorrências concretas de textos específicos.

A perspectiva do significado representacional, a que nos interessa na presente discussão, diz respeito aos discursos enquanto diferentes modos de representação do mundo. Os discursos são visões particulares de mundo mobilizadas ao longo de um texto. Fairclough (2003) propõe, assim como para os demais tipos de significado, uma série de categorias analíticas no âmbito do significado representacional, instrumentos para a operacionalização da análise crítica linguística e socialmente orientada de textos. Uma das categorias mais profícuas para a análise de textos, enquanto eventos sociais inseridos em uma rede de práticas, é a da interdiscursividade.

A análise da interdiscursividade permite a compreensão de que um mesmo texto pode conter, em seu modo de estruturação, diferentes discursos, diferentes perspectivas de mundo, articulados ou relacionados uns com os outros de maneiras diferentes que estão entre a competição e a cooperação. Segundo Ramalho e Resende (2006, p. 72):

A heterogeneidade de um texto em termos da articulação de diferentes discursos é chamada de interdiscursividade. A análise interdiscursiva de um texto relaciona-se à identificação dos discursos articulados e da maneira como são articulados.

Segundo Fairclough (2003, p. 129), a noção de discurso enquanto modo de representação de aspectos do mundo implica na constatação de que, por meio dos diferentes discursos, os atores sociais representam aspectos particulares do mundo de maneiras particulares. Portanto, a análise interdiscursiva deve consistir em dois principais movimentos por parte do analista, para os quais o autor apresenta o seguinte quadro:

Análise interdiscursiva (passos)

(1) Identificar os principais aspectos do mundo (inclusive áreas da vida social) que estão sendo representadas - os principais 'temas'.

(2) Identificar a perspectiva particular, ou ângulo, ou ponto de vista a partir do qual eles são representados.

Fairclough (2003, p. 129, tradução nossa) 
Dessa forma, a análise interdiscursiva fornece um panorama privilegiado para o entendimento da maneira segundo a qual um texto se inscreve no interior das lutas hegemônicas.

Uma perspectiva analítica com tal orientação pretende culminar numa compreensão do discurso em sua realidade de ação política, orientada para fins específicos, e tendo consequências particulares sobre a vida social. Procura contribuir também para alcançar um sentido renovado das escolhas éticas que antecedem e orientam uma formação discursiva particular, propiciando ao analista, tanto quanto possível, um espírito crítico consequente e responsável.

Já neste ponto, ao tratarmos da dimensão política da articulação (interdiscursiva) de diferentes visões de mundo na composição dos textos, faz-se importante mencionar a problemática dos direitos humanos que fornece ensejo para o presente estudo. Não se pode negar que, contemporaneamente, a questão dos direitos humanos encontra-se em profusão e, justamente por este motivo, tem sido objeto de intenso debate nos espaços acadêmicos, podendo ser considerado um problema simultaneamente social, político, jurídico e linguístico relevante.

Considerando a faceta especificamente discursiva dos processos de (re) construção do sentido de direitos humanos no contemporâneo, podemos investigar, a partir de Fairclough (2003), os tipos de significado ou modos por meio dos quais o discurso atua em meio às práticas sociais. Neste trabalho analisamos especificamente os significados representacionais emergentes nos discursos políticos inaugurais do presidente Jair Bolsonaro, em suas referências à questão dos direitos humanos, notadamente no que diz respeito à interdiscursividade. Segundo Fairclough (2003, p. 133), para empreender a análise da interdiscursividade, o analista pode lançar seu olhar sobre traços linguísticos diversos. Assim, discursos podem ser diferenciados através de relações semânticas (sinonímia, hiponímia, antonímia), traços de vocabulário, aspectos gramaticais, suposições, entre outros.

Procuramos observar quais elementos (do mundo físico, social, cultural) estão presentes nos textos selecionados para análise, assim como quais visões de mundo estão endossadas pelas inclusões / exclusões realizadas. Ainda no âmbito da investigação da interdiscursividade, procurar-se-á observar como os discursos incorporados se relacionam (por oposição, antagonismo, por harmonização, confluência etc.), de modo a procurar perceber direcionamentos ideológicos e relações de poder travadas no interior do discurso e fora dele. 
O texto proferido diante de toda a nação, em seu ato de recebimento da faixa presidencial, em $1^{\circ}$ de janeiro de $2019^{3}$, apesar de ser um texto curto, em termos de vocabulário, apresenta escolhas léxicas de elevada recorrência. Palavras como "Deus" e "família" apresentam-se em grande número de referências diretas no discurso. São sete menções diretas à palavra "Deus" e quatro à palavra "família". Quanto à noção de família, há ainda referências indiretas, tais como a menção a "nossas crianças" e "nossos filhos".

O vocabulário consiste em um aspecto discursivo que encontra grande relevância nas observações de Fairclough (2003, p. 130) e será o mais extensamente utilizado aqui, pois uma forma proeminente de marcar o modo de representação de aspectos particulares do mundo é aquela relacionada aos modos de lexicalização das entidades que o constituem.

Sobre a questão dos modos de lexicalização do mundo, Rajagopalan (2003), ao refletir sobre a problemática da designação, nos chama atenção para o problema da impossibilidade de uma referência neutra. Segundo ele:

Há [no interior de cada designação] um julgamento de valores, disfarçado de um ato de referência neutra. [...] À medida que o leitor vai se acostumando ao rótulo, deixa de perceber que a descrição não passa de uma opinião avaliativa. Como todas as opiniões avaliativas, esta também comporta um outro lado. [...] O perigo está no fato de que o leitor ingênuo ou desavisado tende a confundir descrição com termo referencial, opinião com fato consumado (RAJAGOPALAN, 2003, p. 87, grifo nosso).

A interdiscursividade diz respeito aos modos de representação selecionados em um discurso particular. As escolhas de quais elementos do mundo são mobilizadas no interior de determinado discurso, assim como do modo como esses elementos são significados, são fundamentais para se compreender os significados representacionais construídos em meio a tais discursos. Em outras palavras, pinçar para o interior do discurso certos elementos é propor uma visão particular do mundo, um projeto de mundo. Assim sendo, o discurso serve sempre ao reforço de certas ideologias específicas, associadas a um projeto de poder em suas inserções na luta hegemônica.

As expressões recorrentes no discurso presidencial são alusivas a uma visão tradicional e ultraconservadora da sociedade e das práticas religiosas. Além da recorrência, que de per si poderia não ser argumento suficiente, no decorrer do discurso, há uma série de categorizações e qualificadores presentes nos complexos oracionais, que corroboram o sentido ultraconservador das escolhas léxicas

3. Disponível em: https:/www.gov.br/planalto/pt-br/acompanhe-o-planalto/discursos/2019/discurso-do-presidente-da-republica-jair-bolsonaro-durante-cerimonia-de-recebimento-da-faixa-presidencial 
associadas a valores religiosos e à visão de família. Veja-se, por exemplo, os seguintes recortes:

(1) Respeitando os princípios do Estado Democrático, guiados pela nossa Constituição e com Deus no coração, a partir de hoje vamos colocar em prática o projeto que a maioria do povo brasileiro democraticamente escolheu.

(2) Ideologias [nefastas] que destroem nossos valores e tradições, destroem nossas famílias, alicerce de nossa sociedade.

(3) Podemos, eu, você e as nossas famílias, todos juntos, reestabelecer padrões éticos e morais que transformarão nosso Brasil.

Nestes três recortes, podemos observar, segundo os movimentos analíticos propostos por Fairclough (2003) para a análise da interdiscursividade, que além de "identificar" os discursos particulares, visões de mundo particulares selecionadas para compor o texto em análise - a religiosidade, a noção de família - identificamos um modo particular, um ponto de vista específico segundo o qual tais elementos são representados. Como mencionado acima, a ideologia religiosa é acentuada e exacerbada para além dos limites aceitáveis em um discurso de natureza política em uma democracia representativa e em um Estado laico. A expressão (1), que consiste em um circunstante complexo que antecede o sujeito do complexo oracional, estabelece uma associação lógica (por justaposição) entre três valores que não podem ser associados do ponto de vista da ordem jurídica vigente no Brasil: a democracia, o constitucionalismo, a religiosidade. Há uma incompatibilidade inerente, premente e séria entre tais circunstantes associados. Notadamente quando proferida pelo presidente da república, líder máximo do poder executivo, em um discurso oficial, essa associação precisa ser considerada com séria atenção crítica. Os valores religiosos não podem ser circunstantes que caracterizam, na mesma medida que a ordem jurídica constitucional vigente, os atos de execução do projeto de poder e de nação de um presidente.

No segundo excerto, a visão ultraconservadora de família acionada na fala do presidente manifesta-se na escolha das formas de nomeação e categorização do participante da oração (2) "ideologias" - categorizado, no período anterior do discurso, como "nefastas". Manifesta-se ainda na escolha léxica que designa o processo que está explícito na oração: "destroem". No excerto seguinte, também a designação do processo principal do complexo oracional - "restabelecer" - é indicativa de uma visão conservadora de família, qualificada como aquela que se adequa a "padrões éticos e morais". Uma visão muito particular de família é acionada 
na fala do presidente, a visão tradicional, associável inclusive à definição religiosa dessa instituição.

Entendemos que os gestos de significação e as estratégias discursivas destacadas na análise acima contribuem para o apagamento do sentido jurídico e valorativo dos direitos humanos, notadamente no que diz respeito à família e à liberdade religiosa e de pensamento. A afirmação de um Estado de direito laico, fundamentado em uma ordem jurídica que promova o respeito a direitos e liberdades, é condição fundamental para a plena realização da dignidade humana, inclusive no que diz respeito a sua liberdade de professar uma fé, manifestar sua religião ou crença.

Uma vez que se trata de um discurso político, podemos afirmar que essas escolhas linguísticas, associadas a outras presentes nessa mesma fala, compõem uma configuração discursiva associada ao exercício do poder político do presidente. Em sua visão antagônica e essencialmente política da vida social, Ernesto Laclau (2013) reconceitua o populismo, entendendo-o como elemento fundamental do político, elemento constitutivo do social. Ao pinçar para o interior de seu discurso representações ultraconservadoras, o presidente associa-se a um grupo de pessoas, que balizam seu discurso, que se identificam com ideologias de extrema direita. Assim, o discurso de Bolsonaro é estrategicamente populista, no sentido postulado por Laclau, uma vez que serve a um projeto hegemônico. Emergente do cenário político conturbado do Brasil, o discurso organiza-se por completo em torno do acirramento de oposições e antagonismos, passíveis de serem analisados nos sentidos construídos em meio ao seu discurso, isto é, nas escolhas discursivas mobilizadas para nomear (significar) os elementos das oposições fundamentais que marcam as tensões sociais no Brasil contemporâneo.

Trata-se da negação do inimigo, a construção de uma imagem de confronto e da afirmação de força política e representatividade para confrontar esse "inimigo". Segundo Laclau, o domínio do político é construído antes pelo conflito e pela divisão do que pela afirmação, pela unificação. Em consonância com essa ideia, as escolhas linguísticas emergentes no discurso do presidente são majoritariamente negativas. Nos textos selecionados, os direitos humanos são invocados para serem negados e não afirmados, seu sentido é depreciado como parte de uma estratégia política. Vejamos os exemplos seguintes, extraídos do mesmo discurso em estudo:

(4) Temos o grande desafio de enfrentar os efeitos da crise econômica, do desemprego recorde, da ideologização de nossas crianças, do desvirtuamento dos direitos humanos e da desconstrução da família. 
(5) Também é urgente acabar com a ideologia que defende bandidos e criminaliza policiais, que levou o Brasil a viver o aumento dos índices de violência e do poder do crime organizado, que tira vidas de inocentes, destrói famílias e leva a insegurança a todos os lugares.

(6) Nossa preocupação será com a segurança das pessoas de bem e a garantia do direito de propriedade [...]

No complexo oracional (4), as expressões preposicionadas que são enumeradas, com função gramatical de complementos nominais do núcleo "efeitos" - "da crise econômica", "do desemprego recorde", "da ideologização de nossas crianças", "do desvirtuamento dos direitos humanos", "da desconstrução da família" - apresentam um paralelismo não apenas sintático, mas também semântico. Estão justapostas e enumeradas com o fim de "classificar" qual é o inimigo a ser combatido. Apresentam, inclusive, o acúmulo da negação, como por exemplo, o duplo recurso ao emprego do prefixo negativo "des-". A escolha por tais representações, mais uma vez comprometidas com uma visão de mundo conservadora associável à extrema direita, contrariam e silenciam o sentido contemporâneo de direitos humanos. Concebidos como uma ordem de regras e princípios voltados para afirmar a higidez da dignidade humana, com fundamento na liberdade e na justiça, assim como na paz entre os povos, os direitos humanos constituem uma plataforma emancipatória de direitos que devem ser amplamente reconhecidos e aplicados.

Ainda no exemplo (4), essa justaposição de expressões consiste, no fim das contas, nas diferenças que são articuladas pelo discurso em questão para se constituir e legitimar-se, ou seja, nos elementos que são articulados (e transformadas em momentos) não apenas para demarcar a fronteira entre um dentro e um fora, um Eu e um Outro, mas, sobretudo para mostrar que uma nova hegemonia política está em curso no Brasil: a hegemonia do ideário da extrema direita, cuja forma de legitimação se dá pela articulação de elementos ou diferenças cujos conteúdos são esvaziados, entre elas, a noção de direitos humanos.

Não à toa, logo em seguida esse discurso articula o elemento "desvirtuamento dos direitos humanos" com outros elementos: "os efeitos da crise econômica", "do desemprego recorde", "da ideologização de nossas crianças" e "da desconstrução da família". Todos esses elementos ou diferenças são articulados em torno de um ponto nodal para a construção de uma equivalência, ou seja, o reestabelecimento de uma ordem, como é próprio aos discursos de viés conservador. É importante enfatizar, no que diz respeito à referência a Laclau e Mouffe, que a apropriação da noção de direitos humanos no discurso da extrema direita se dá enquanto uma das diferenças articuladas por esse discurso em suas estratégias de legitimação, 
articulação esta que se dá ora em função de uma torção da forma como essa noção é pensada no interior do discurso jurídico (em enunciados como "direitos humanos para humanos direitos"), ora em função do esvaziamento dessa noção.

No exemplo (5) destacamos mais um gesto de apagamento do status jurídico dos direitos humanos. A escolha do processo verbal "acabar" demarca novamente a construção da representação do inimigo: a ideologia, uma certa ideologia. A oração subordinada com função de qualificadora do núcleo nominal "ideologia" evidencia ainda mais a estratégia discursiva em curso. A ideologia inimiga é, especificamente, aquela "que defende bandidos e criminaliza policiais". Trata-se de alusão muito clara a uma visão recorrente no senso comum das pessoas que se orientam por uma visão ultraconservadora de mundo e que poderia ser traduzida na expressão popular: "bandido bom é bandido morto". Novamente, os direitos humanos são esvaziados em seu conteúdo normativo. Preceitua a Declaração Universal dos Direitos Humanos, em seu art. $7^{\circ}$ que "Todos são iguais perante a lei e têm direito, sem qualquer distinção, a igual proteção da lei". Direitos humanos fundamentais como o direito a igualdade e outros associados a este - tais como o princípio de presunção da inocência, o direito a um julgamento justo, ao devido processo legal etc. - são adulterados na fala do presidente.

Por fim, no excerto (6), mais uma expressão com forte eco no senso comum ultraconservador - "pessoa de bem" - surge como escolha de designação que tem dois direcionamentos principais: (i) associar o presidente ao grupo de seus apoiadores, uma afirmação de legitimidade e representatividade das suas ações e posições enquanto presidente; e (ii) segregar, em sua fala, um grupo a quem se voltam as garantias estatais no exercício do poder político atual: as pessoas de bem. Esse segundo direcionamento contraria o direito humano fundamental ao reconhecimento como pessoa, a personalidade jurídica. "Toda pessoa tem direito de ser, em todos os lugares, reconhecida como pessoa perante a lei" (Declaração Universal dos Direitos Humanos, art. $6^{\circ}$ ).

Para finalizar o recorte de análise aqui proposto, observemos um trecho do primeiro discurso internacional proferido pelo presidente eleito, no Fórum Econômico Mundial, em Davos, ainda no primeiro mês de governo ${ }^{4}$.

(7) Vamos defender a família e os verdadeiros direitos humanos; proteger o direito à vida e à propriedade privada e promover uma educação que prepare nossa

4. Disponível em: https://www.gov.br/planalto/pt-br/acompanhe-o-planalto/discursos/2019/discursodo-presidente-da-republica-jair-bolsonaro-durante-a-abertura-da-sessao-plenaria-do-forumeconomico-mundial-2019 
juventude para os desafios da quarta revolução industrial, buscando, pelo conhecimento, reduzir a pobreza e a miséria.

Nesse trecho, a escolha pela expressão atributiva "verdadeiros" para qualificar os direitos humanos é sintomática da estratégia populista emergente no discurso do presidente. Por meio dela, as associações apontadas anteriormente, que formam um amálgama a partir do qual se constrói a ideia de um inimigo comum, agora são postas em relação de equivalência com a Verdade. Há uma equivalência estabelecida entre o discurso do presidente, sua visão dos direitos humanos, e a "Verdade". Em sua fala, ele seria o porta-voz dos direitos humanos verdadeiros. Mais uma vez, trata-se de uma estratégia de unificação de grupos aderentes a si, por meio da negação de sua alteridade.

Em outros contextos, o presidente Bolsonaro lançou mão deste mesmo expediente, de construir uma imagem para si daquele que possui a verdade, de mensageiro da verdade. Um exemplo emblemático foi sua manifestação no Twitter, em que ele contesta a procuradora Simone Sibilio, responsável por investigações relacionadas à morte de Marielle Franco, utilizando um versículo bíblico em sua postagem: "Conhecereis a verdade e a verdade vos libertará" (Jo 8:32). Além disso, muitos de seus seguidores (e até mesmo ele próprio), usam a designação "messias" (alusiva ao seu nome), com viés religioso para referir-se a ele. Segue a imagem do tuite:

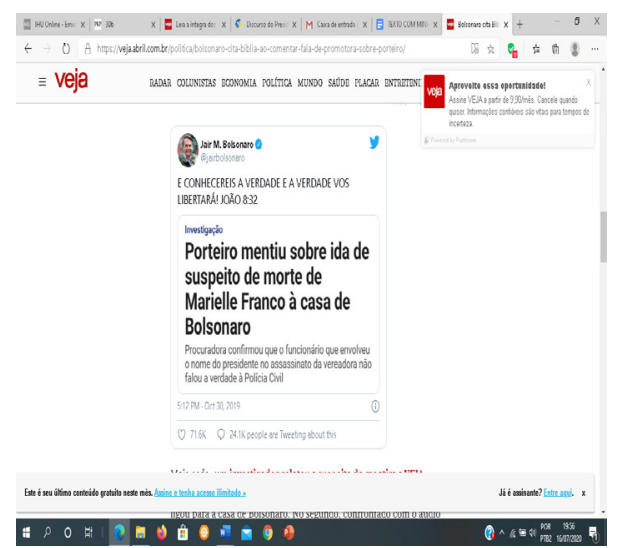

Fonte:https://veja.abril.com.br/politica/bolsonaro-cita-biblia-ao-comentar-fala-de-promotora-sobre-porteiro/

Como sinalizaram as exposições até aqui, todos esses fenômenos de linguagem partem de uma compreensão do discurso inserido em redes de práticas sociais. Tal 
posicionamento das questões de linguagem contribui para situar a reflexão acerca de questões linguísticas naquela região privilegiada em que estruturas e eventos, nas teorizações de Fairclough $(2001 ; 2003)$, se tocam e se determinam mutuamente.

Uma análise segundo esse viés procura, portanto, o que podemos chamar, segundo Rajagopalan (2003), de uma política de representação construída no âmbito das práticas sociodiscursivas focalizadas, através de uma abordagem do discurso em sua profunda relação com práticas sociais mais amplas. Esse tipo de análise finda por demonstrar a íntima relação existente entre as representações postas em cena nesse discurso e as disputas ideológicas em torno de projetos de poder.

Dessa forma, podem-se entender as representações não como construções individuais, mas como variáveis socialmente construídas e socialmente contestadas, facetas de processos culturais mais amplos. Assim, cada um dos sentidos mobilizados para construir discursivamente os direitos humanos constitui um lance de linguagem numa arena de lutas que envolve conflitos de interesses e tensões sociais e que, por isso, reclama de forma urgente uma análise crítica, isto é, que leve em consideração o fato de que se trata de um ato de linguagem com implicações e consequências, para o bem ou para o mal.

\section{CONSIDERAÇÕES FINAIS}

"Sentir a vida convalesce e estiola" (Álvaro de Campos)

Como pudemos perceber neste trabalho, os direitos humanos vêm sendo concebidos contemporaneamente como plataforma emancipatória de direitos voltados para a preservação da higidez da dignidade humana. Gestados no seio do discurso do direito tendo como fundamento uma representação universal em termos clássicos, isto é, uma visão essencialista do humano, sua construção contemporânea traz impressa a marca da particularização, da singularidade que atravessam os contextos de violação (exclusão). De certa maneira, é possível afirmar que a construção da representação dos direitos humanos nos tempos presentes está umbilicalmente relacionada com a afirmação cada vez mais contundente do caráter plural do nosso mundo, com o avivamento da consciência de sua realidade multifacetada, deslocada do seu centro, em plena falência das velhas metanarrativas que o sustentaram. De acordo com Boaventura de Souza Santos (2009), uma das tarefas prévias à construção de uma concepção multicultural de direitos humanos é a extensão da consciência de incompletude cultural. 
Esta problemática, simultaneamente linguística, jurídica e sociológica, foi abordada tendo como referencial teórico fundamental a Análise de Discurso Crítica, de Norman Fairclough ([1992] 2001; 2003), com sua visão crítica do discurso em relação indissociável com o mundo social. Além dessa base teórica principal, as análises que empreendemos dialogaram com o pensamento social crítico de Ernesto Laclau e Chantal Mouffe, através de conceitos como hegemonia, antagonismo, significante vazio, populismo.

Neste trabalho, ao propor a análise de discursos políticos que engendram o cenário político brasileiro atual, procuramos responder à demanda urgente e necessária de fortalecer o reconhecimento e a observância dos direitos humanos no Brasil. Queremos chamar atenção para o fato de que, nos discursos de Bolsonaro, destaca-se um processo de ressignificação dos direitos humanos, que surgem como tema recorrente em suas falas. De acordo com as reflexões aqui propostas, a (re) construção de sentidos para direitos humanos faz parte dos mecanismos semióticos que sustentam as forças políticas que ocupam o poder no Brasil atual.

Austin (1962) já havia nos chamado a atenção para o potencial performativo da linguagem. Um poder edificante, quase mágico, de dar a existir realidades. Ele nos alertou o quanto a linguagem está além da designação, da semiotização da vida. Ela "cria" o mundo, dá a existência das coisas, uma vez que é por ela que conhecemos as coisas. Se, há algum tempo, a linguística (notadamente a linguística aplicada) tem sentido advertidamente a necessidade de confrontar esse potencial performativo, "desconfiando" de que seria a linguagem parte fundamental e edificante da vida social, hoje os linguistas convalescemos e estiolamo-nos dessa mesma necessidade. Vivemos sob a égide de uma conjuntura política cuidadosamente arquitetada em semiose (discurso). Um estado de poder, uma hegemonia, fundada em estratégias semiótico-discursivas precisas, que preenche os limites contingentes do presente.

Neste trabalho, procuramos entender o caráter discursivo das instituições jurídicas, notadamente dos direitos humanos. O interesse é demonstrar como, para além de instituições - que efetivamente o são, constituindo-se em uma ordem mandamental que regulamenta e se sobreleva à vida social - os direitos humanos são construções discursivas, discursos, que mobilizam representações específicas, excluem outras, e que o fazem de uma maneira particular (e não outra). Assim, o jogo semiótico-discursivo para dar sentido ao direito, à justiça, aos direitos humanos constitui o nosso mundo em realidade, e é parte fundamental do confronto de forças que culminou no estado hegemônico instaurado hoje no Brasil. Este trabalho tem o objetivo primordial de afirmar, de forma responsiva (e, apesar de tantos avanços na linguística crítica, ainda revolucionária), que o direito é discurso; que os direitos 
humanos são discurso. E, como tal, reclamam atenção séria e urgente. O direito e as instituições jurídicas estão enredados na mesma teia problemática do discurso, com toda a temeridade, estiolamento e premência que esta afirmação carrega, ao tratar do Brasil contemporâneo.

\section{REFERÊNCIAS}

AUSTIN, John Langshaw. How to do things with words. London: Routledge, 1962.

BOLSONARO, Jair. Discurso do Presidente da República, durante cerimônia de Recebimento da Faixa Presidencial. Publicado em 01/01/2019, 16h45. Disponível em: https://www.gov.br/planalto/pt-br/acompanhe-o-planalto/discursos/2019/discursodo-presidente-da-republica-jair-bolsonaro-durante-cerimonia-de-recebimento-dafaixa-presidencial

BOLSONARO, Jair. Discurso do presidente da República, durante a abertura da sessão plenária do Fórum Econômico Mundial 2019. Publicado em 22/01/2019. 13h30. Disponível em: https://www.gov.br/planalto/pt-br/acompanhe-o-planalto/discursos/2019/discursodo-presidente-da-republica-jair-bolsonaro-durante-a-abertura-da-sessao-plenaria-doforum-economico-mundial-2019

CAVALCANTI, M. C. G. M. Direitos bumanos como significante vazio: modos de agir, modos de representar e modos de ser na luta (discursiva) por direitos. Tese de doutorado - Universidade Estadual do Ceará. Fortaleza. 2016.

FAIRCLOUGH, Norman. Discurso e mudança social. Brasília: Editora Universidade de Brasília, 2001.

FAIRCLOUGH, Norman. Analysing discourse: textual analysis for social research. London: Routledge, 2003.

FERREIRA, Ruberval. A questão da representação na Análise de Discurso Crítica: algumas questões para o debate. In: MAGALHÃES et al. Anais do Seminário de Análise de Discurso Crítica. Fortaleza: UFC, 2010.

FERREIRA, Ruberval, RAJAGOPALAN, Kanavillil. Um mapa da crítica nos estudos da linguagem e do discurso. São Paulo/Campinas: Pontes Editores, 2016.

FLORES, Joaquín Herrera. Direitos bumanos, interculturalidade e racionalidade de resistência. Rio de Janeiro: Mimeo. 1991. 
LACLAU, Ernesto. New reflections on the revolution of our time. London: Verso, 1990.

LACLAU, Ernesto. A razão populista. Três estrelas: São Paulo, 2013.

LACLAU, E.; MOUFFE, C. Hegemonia e estratégia socialista: por uma política democrática radical. Trad. Joanildo A. Burity; Josias de Paula Jr.; Aécio Amaral. São Paulo: Intermeios Casa de Artes e Livros, 2015.

LAFER, Celso. A reconstrução dos direitos bumanos: um diálogo com o pensamento de Hannah Arendt. São Paulo: Companhia das Letras, 1988.

PIOVESAN, F. Direitos bumanos e justiça internacional. 2 ed. São Paulo: Saraiva, 2011.

RAJAGOPALAN, Kanavilil. Atos ilocucionários como jogos de linguagem. Estudos linguísticos. Lorena, n. 18, p. 523-530, 1989. Anais de Seminários.

RAJAGOPALAN, Kanavilil. Por uma linguística crítica: linguagem, identidade e a questão ética. São Paulo: Parábola Editorial, 2003.

RAMALHO, V.; RESENDE, V. M. Análise de discurso crítica. Campinas: Pontes, 2006.

SANTOS, Boaventura de Sousa. Direitos humanos: o desafio da interculturalidade. Revista Direitos Humanos, 02, junho/2009.

Recebido: 20/2/2020

Aceito: 20/7/2020

Publicado: 20/7/2020 